\title{
Creativity in Organizational Environment
}

\author{
Eva Szobiová ${ }^{*}$
}

\begin{abstract}
The contribution is focused on the conditions which allow the application of creativity in the context of an organization. The aim of the article is to reveal the work environment factors influencing the creativity of the employees. Another aim is to demonstrate how management style of an organization can affect the creativity of employees in order to successfully exploit their creative potential. The contribution also presents the manner how a manager can influence creativity of one's own employees. Moreover, the article deals with the process of innovation and transmission of creative ideas and solutions into practice.
\end{abstract}

Key words: family, upbringing, father's role, mother's role.

\section{Introduction}

It is widely recognized that important inventions and discoveries of the past and the present day were born in the minds of exceptional people. Nowadays, Richard Florida and Jim Goodnight (2005) call these extremely creative individuals the creative class, which represents about one third of the labour force in the U.S. economy. The authors state that each month the creative class is credited an amount equal to almost half of all wages in the U.S. to their bank accounts. It is clear that the platform for the emergence of creative ideas represents the conditions that enable success even in the current competitive and saturated economic situation. What are the conditions that allow exploiting the creative potential of the people in the organization? What are the factors of the working environment of the organization that affect creativity in a positive or negative way?

\section{Creativity in Organization}

Organizational creativity is usually considered to be "the creation of valuable, useful new product, service, idea, procedure, or process by individuals working together in a complex social system." (Woodman, Sawyer \& Griffin, 1993, p. 293). Currently, organizational creativity stands for the production of high quality, original and elegant solutions to problems (Mumford et al., 2012).

\footnotetext{
* Eva Szobiová, Pan-European University, Bratislava, Slovakia; eva.szobiova@paneurouni.com
} 


\section{Acta Technologica Dubnicae \\ volume 5, 2015, issue 2}

Creativity in an organization is a complex phenomenon that has different levels. It can be viewed from individual, group and organization perspectives.

\section{Individual creativity}

There are many studies confirming a large number of personal and sociopsychological characteristics at the individual creativity level that are positively associated with creativity. Among them we can mention sensitivity to problems, a broad range of interests, high valuation of aesthetic qualities, interest in complex problems, independence, autonomy, self-confidence, playfulness, intuitiveness, forcefulness (Barron \& Harrington, 1981), tolerance for ambiguity, stimulation and functional freedom, flexibility, willingness to take risks, complexity preference, postponement of satisfaction, abandonment of gender role stereotypes, perseverance, courage (Dacey \& Lennon, 2000), curiosity, causal reasoning. The characteristics negatively related to creativity include conformity and power (Rice, 2006, in Klijn \& Tomic, 2010). Since this list of characteristics was not predictable for creativity at work, the perceived creativity was examined in an individual that might have greater predictive power. Gardner and Pierce (1998, in Klijn \& Tomic, 2010) believe that individuals, that self-evaluated themselves as persons with a higher level of creativity, will implement more creative ideas in practice. According to Pretorius (2005, in Klijn \& Tomic, 2010) the highest self-perceived level of creativity is reported in people who have experience with management (ideally 3-5 years), namely in mature organizations.

Another factor that affects creativity at the individual level is age. Previous research has shown that the most creative contributions (major contributions) occur in young adulthood. The number of these contributions sharply decreases at the end of early adulthood, and a number of smaller creative contributions remains relatively constant and then begins to decline slowly as an individual reaches half of the sixties (Lehman, 1966, in Klijn \& Tomic, 2010).

One of the most frequently cited terms of creativity at the individual level is the ability of divergent thinking, which is often confused with creativity itself. The definition of creativity in the work context stated by Amabile (1983) is divergency (taken as novelty or originality) in addition to usefulness as one of the essential characteristics of creative solutions. It allows creating new and unconventional solutions, which are the distinguishing features of convergent thinking that is connected with finding the one correct answer. Among other factors which influence cognitive performance, we can include intelligence. There has been proven a positive relation between IQ (up to 120 score) and creativity. Above this value, no strong relation between these two has been noticed. Therefore, there is a limit or threshold of intelligence upon which creativity is dependent on other components.

Other components also include motivation and emotion. Thanks to her qualitative examination, Amabile (1983) found out that positive emotions not 


\section{Acta Technologica Dubnicae \\ volume 5, 2015, issue 2}

only precede creative ideas, but they are also present during the process of creative thinking and even after the events, which include creative ideas. If organizations want their employees to bring creative ideas and solutions, it is necessary not only to have positive atmosphere but also intrinsic motivation in an individual that should dominate. Besides this motivation, attention control, self-control and the way an individual sets goals play important roles. These factors of self-regulation influence the degree of intrinsic motivation despite the factors coming from the external environment (e.g. bonuses, awards).

\section{Group creativity}

Creativity at group level is affected by many factors such as membership changes within the group (Choi \& Thompson, 2005, in Klijn \& Tomic, 2010), formal and informal contacts (Kratzer el al, 2005, in Klijn \& Tomic, 2010) and group climate (Mathisen et al., 2004, in Klijn \& Tomic, 2010). A change in group membership usually means the arrival of new members. Open groups with looser membership have higher level of creativity accompanied by higher production of ideas and solutions in comparison with closed groups. New members of the group have a positive impact when their knowledge, experience and skills are comparable with those of the other members of the group. The arrival of new members often has a positive impact on the performance of established employees. Informal relationships in the workplace in terms of impact on creativity are frequently examined, but with contradictory results. Studies have focused on the effects of considerate, kind relations (friendly ties) and friendship (friendships ties) in teams. While friendships (at which contacts continue outside the work environment) have only positive effects on creativity, considerate and kindly relations (they do not continue outside the workplace) affect the creativity of the teams in the U-shaped curve. Hence we can conclude a recommendation for managers in organizations: in order to increase creativity we should try to build not only formal but also informal relationships with colleagues (Kratzer et al., 2005, in Klijn \& Tomic, 2010).

In addition to the quality of relationships in the workplace, climate is a key factor as well. There are four determinants of climate in the workplace (Mathisen et al., 2004):

1. Clearly defined and shared vision that focuses and directs the energy of the group members.

2. Let each group member participate in decision-making processes.

3. Working environment perceived as safe - that is, each group member may, without fear of criticism, present new views and ideas.

4. Spoken and given support for new and improved ways of working from management and colleagues.

Climate favouring creativity is characterized by a focus on learning, psychological safety and willingness of members to share ideas (self-disclosure). 


\section{Acta Technologica Dubnicae \\ volume 5, 2015, issue 2}

Although much research has underlined the need to reduce conflicts and criticism in order to promote creativity, there is evidence that criticism and sometimes group conflict can have a positive impact on the creation of new ideas (James, 1995, in Klijn \& Tomic, 2010; Nemeth et al. 2004, in Klijn \& Tomic, 2010). An important factor to be taken into account in team creation is also the interdisciplinarity, knowledge and skills of individual members. Diversity of their knowledge and background has demonstrated a positive impact on the creativity of the whole group (Woodman et al. 1993, in Klijn \& Tomic, 2010). Paulus (2000, in Klijn \& Tomic, 2010) divided negative factors influencing creativity into 2 groups:

- Social inhibitors (social anxiety, social loafing, illusion of productivity, and downward comparison).

- Cognitive interference (production blocking, behaviour irrelevant to the task and cognitive overload).

On the other hand, factors positively affecting creativity are social stimulators (competition, personal responsibility, comparison upwards) and cognitive stimulators (new association, attention, conflict, heterogeneity and complementarity between group members, divergent thinking and time for incubation of ideas).

\section{Organizational creativity}

Research (Hemlin, 2006) has shown that team leadership is more important than the help of organization when considering creativity at the organizational level. This was proven by several case studies (Woodman et al., 1993; Paulus, 2000; Florida \& Goodnight, 2005) that examined factors affecting creativity at the level of organization. These factors are as follows:

- Cultural influences;

- Resources availability;

- Reward policies;

- Mission and strategy of the organization;

- Organizational structure and technology.

Although it is very difficult to measure the impact of individual factors at this level, case studies have shown that the existence of the listed components promotes creativity within the whole organization (Paulus, 2000). One of the case studies in small business (over 30 employees) showed that creativity can be supported by avoiding hierarchy, creating flexible jobs, emphasizing mutual enrichment (cross-fertilization). Decrease of creativity occurs in organizations that are highly centralized and formalized, where the groups consciously or unconsciously hinder innovation process (Paulus, 2000). Harmony, group conformity and interdependency help collectivist cultures, while individualistic 


\section{Acta Technologica Dubnicae \\ volume 5, 2015, issue 2}

cultures appreciate uniqueness and independence. Results of several studies have confirmed that individualistic values contribute to creativity. If creativity is the organization's goal, individualistic culture appears to be preferable. Organizations that plan ahead and identify the potentially significant problems at their early stage, provide employees with sufficient information and support troubleshooting bring more creative outcomes. Highly creative employees thrive in an environment of challenges, which are managed by supporting and noncontrolling manner. On the other hand, employees with low creativity are stressed and irritated in such conditions that lead them to even less creativity. With regard to the creativity factors identified at the organizational level, it should be a challenge for the organization to design a context and outline a strategy that maximizes creative work performance, taking into account individual differences. Management's efforts to increase organizational creativity are connected to consideration of personal as well as contextual factors (Oldham \& Cummings, 1996).

In order to zoom at organizational creativity in its complexity, we present a creative change model suggested by Puccio, Murdock and Mance (2007, in Puccio \& Cabra, 2010). This model uses a system approach and provides a framework to a set of variables that are related to organizational creativity. The model shows that creativity and innovation in an organization are the results of interactions between people, processes, in which they are included, and also the environment in which they work.

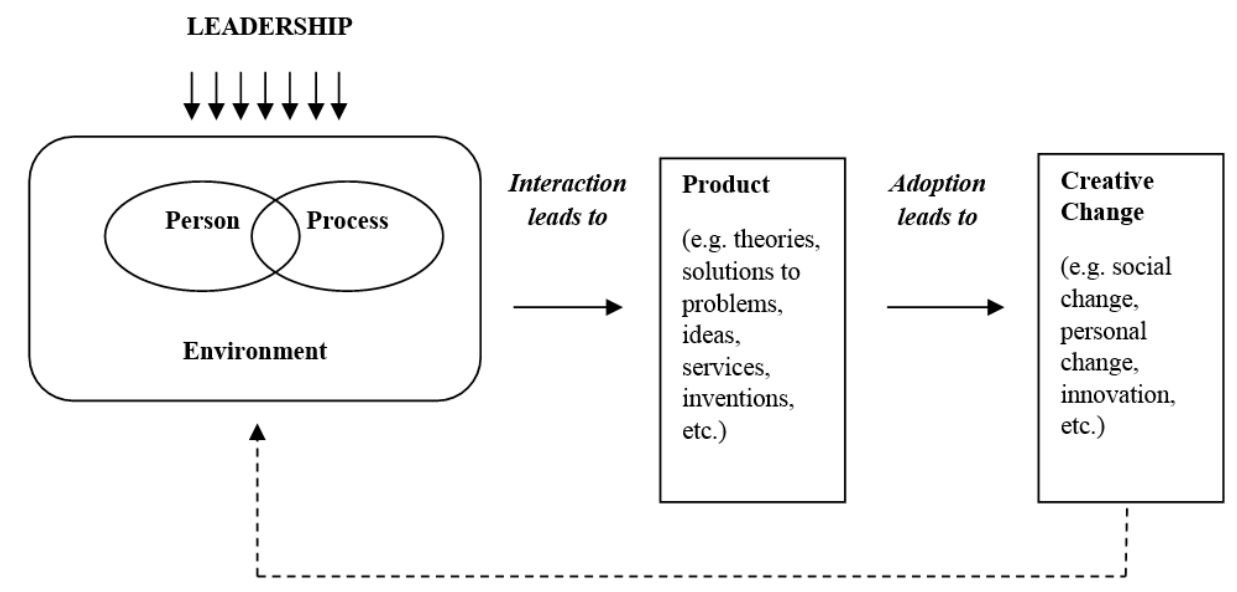

Figure 1. Creativity: System Model (Puccio \& Cabra, 2010, p. 148) 


\section{Acta Technologica Dubnicae \\ volume 5, 2015, issue 2}

Let us explain all of the aspects. First of all, aspects of a person relate to skills, background, experience, personality, knowledge, motivation of the individual and its other properties. Process refers to the stage of thinking of people, when they work alone or with others and head to creative preparation or to exploit opportunities for creativity at work. The last but not least, environment refers to psychological as well as physical conditions in which the person works.

The interplay of these aspects leads to tangible or intangible product (that is problem solving, expressing new ideas, bringing new offers, invention, etc.). Until the product of creative thinking is not recognized, the creative effort continues and a change is adopted, at least temporarily. When the product is internally approved, changes resulting from creativity can lead to lower prices, improvement of strategies or procedures, to new business models, etc. Externally oriented products result in changes in the market such as a successful introduction of innovative products and services.

This interactive system model (Fig. 1) shows how acceptation of internal or external changes consequently affects the organization and how it potentially affects people, processes and the environment in the organization. It includes not only the fundamental aspects of creativity (person, process, product, environment), but also another core element of the organizational creativity leadership/management. Even more recent literature particularly emphasizes the influence of leaders on group and organizational creativity.

The major trend in organizational creativity is devoted to the role of management/leadership in fostering creativity in the workplace. Organizational behavior that supports or, on contrary, undermines creativity, is currently classified as the most important factor in the organizational context by many authors. Although recent research, which is devoted to top-level managers, showed that top management plays a critical role in introducing innovation in the organization. The impact of management/leadership is reflected not only at the organizational level, but group level as well (Puccio \& Cabra, 2010).

Ekvall (1996) analyzed and compared innovative and stagnant organizations, and created a questionnaire to identify creative climate (the Creative Climate Questionnaire - CCQ), which describes 10 of its dimensions: challenge, freedom, idea support, trust/openness, dynamism/liveliness, playfulness/humor, debates, conflicts, risk, and time for ideas. According to Ekvall, these 10 dimensions stated by research differentiate between organizations that are highly innovative and those that are stagnating. The following dimensions are crucial for innovation: challenge, freedom, trust, playfulness and low existence of conflict. 


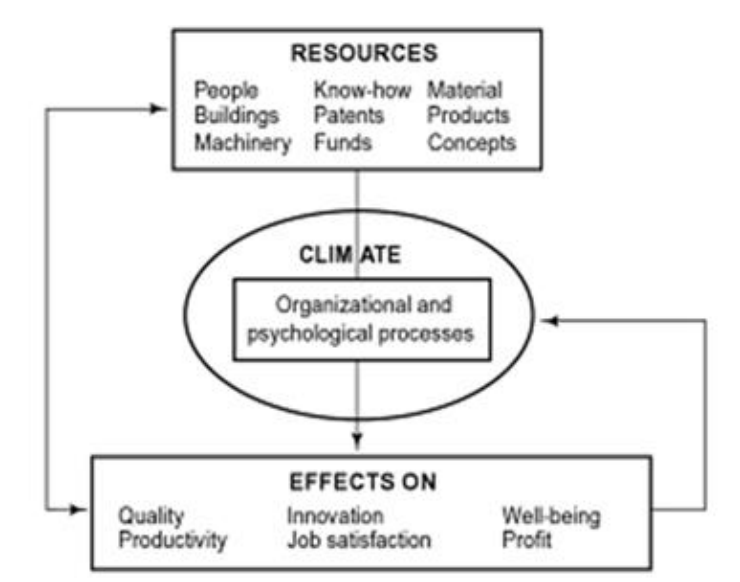

Figure 2. Organizational climate as an intervening variable (Ekvall, 1999, p. 405)

Within the organizational processes, climate plays a role as an intervening variable (see Fig. 2) and thus affects the results of business of the organization. Climate has a modifying power as it has an impact on organizational processes such as problem solving, decision making, communication, coordination, control and psychological processes of learning, creative production, motivation, determination and commitment. Organizations have different types of resources - people, money, equipment, etc. They use them in their processes and operations. These operations bring different kinds of effects at different levels of abstraction: high or low quality products or services; radically new products or only small improvements in older products; high or low well-being in the relationship between employees and business profit or loss. Climate strongly affects results, but on the other hand, these results affect the financial aspects as well as the climate itself. These causal relationships are very complex and can be identified as interconnected factors.

According to Amabile et al. (1999, in Puccio \& Cabra, 2010), important dimensions supporting or undermining creativity in the environment include:

a) Stimulators: encouragement of the organization and supervision, support of a working group, sufficient resources, operational challenges, freedom.

b) Inhibitors: organizational barriers, work overload and work pressure. Cabra and Joniak (2006, in Puccio \& Cabra, 2010) add to the supportive dimensions also confidence, responsibility, management/leadership style, synergy, dynamism, time for ideas, building confidence, influence of management norms, solidarity, and sense for justice. They add envy and jealousy into a group of undermining dimensions. 


\section{Acta Technologica Dubnicae \\ volume 5, 2015, issue 2}

Creative climate characterized by Pagano (1979) is an "open" environment or a "free" environment in which an individual can express one's thoughts, ideas and emotions and where one feels safe. It is the environment that has its rules, but the manager is not authoritative and dominant.

According to Amabile (1983), creativity results from certain constellations of personality traits, cognitive abilities, and social environment. She also builds on her interactionalist model of creativity, which points to four groups of factors:

1. Prior conditions - these are individual characteristics that result in differences in creativity and affect cognitive and personality characteristics; they include learning, early socialization and the characteristics of environment.

2. Cognitive factors - are mainly represented by intelligence, divergent and convergent thinking, cognitive style (dependence or independence of the field), and others.

3. Personality factors.

4. Contextual and social factors - include the physical environment, culture, group climate, expectations, rewards or punishment.

Amabile (1998) advocated theoretical concepts and their application in practice, particularly in an effort to develop a creative environment and to encourage employee creativity. She had studied organizations for 22 years and found that creativity is more often undermined rather than supported, despite the fact that most managers believe in the value of new and useful ideas. Her research shows that it is possible to develop both worlds: an organization in which the imperatives of business are needed as well as creativity that enriches work. Building organizations requires detailed knowledge and understanding of how management, management practices, procedures encourage or undermine creativity. Amabile states three components of creativity in every individual:

1. Expertise knowledge and skills in the field - technical, procedural, intellectual,

2. Creative thinking and skills,

3. Motivation to solve the problem.

Managers can support these three components in jobs and conditions. Skills, creative thinking skills affect flexibility and imagination in problem solving. Amabile (1983) experimentally investigated the impact of the type of motivation for creativity and confirmed the importance of intrinsic motivation for expressing creativity. She found that intrinsic motivation encourages people more and it also more often leads to creative solutions than extrinsic motivation (e.g. in the form of bonuses, money). Intrinsic motivation can be even supported in the workplace. It turned out that environments promoting intrinsic motivation support creativity more than environments preferring extrinsic motivation. 


\section{Acta Technologica Dubnicae \\ volume 5, 2015, issue 2}

Certain types of extrinsic motivation may encourage creative potential particularly situations in which the parameters of ongoing success are clearly formulated. If a person works in an environment where activity is continuously evaluated and one is rewarded and appreciated, thanks to these external factors intense internal charge could emerge (Žák, 2004). Even Eisenberger (1996) found in research that rewards can be effective in enhancing creativity. Amabile and Hennessey (1992) improved the concept of extrinsic motivation in relation to the creative aspects. They added the aspects of control and information. At the same time, they identified two types of extrinsic motivation:

a) Synergistic external stimuli that provide information and help an individual to perform a task more efficiently. They may be in line with internal motivation.

b) Non-synergistic external stimuli, in which an individual perceives control and which are not in line with the inner motivation.

Extrinsic motivation in terms of information provision becomes effective in situations where the initial level of intrinsic motivation is high and, consequently, external stimuli can lead to creativity by encouraging tendency to participate in tasks actively. Amabile and Hennessey (1992) emphasize the finding that, for example, professional artists - people working in creative environments - have a tendency to be more intrinsically motivated in their work compared to the general population.

Amabile (1998) identified six major categories of manager leadership in her research that can affect creativity: challenge, freedom, resources, support of the working group, encouragement in supervision, and support in the organization.

Work environment and its impact on the creativity of employees or the effects of climate on creativity in an environment were also examined by several authors in Slovakia and the Czech Republic (e.g. Fichnová, 2013; Jurčová, 1995; Kolajová, 2009; Mikuláštik, 2010; Tamášová \& Barnová, 2011). Zelina and Jaššová (1984) distinguished the factors for and against creativity. According to Jurčová, Kusá and Kováčová (1995, p. 47), the most frequently mentioned environmental factors facilitating creativity are as follows:

- Idea time

- Challenge

- Support

- Debate

- Freedom, playfulness, dynamism.

Hennessey and Amabile (1988) focused on interactionalist understanding of relations: person- environment- creativity. They stressed not only the individual psychological perception of the social environment, but also the characteristics of a particular person. Their studies confirmed that the same environmental conditions may be perceived differently by different people who differ in 


\section{Acta Technologica Dubnicae \\ volume 5, 2015, issue 2}

specific personality dimensions. They compared high and low creative individuals whose intrapersonal characteristics were different. When compared with individuals with low originality, the highly creative ones perceived humour in the climate more positively. Those highly original individuals, whose personality traits had a significant prosocial aspect, perceived: sociability, confidence in others, nature, accessibility, and overall looseness. From social capabilities, empathy was the most associated with perception. Highly original individuals who are more closed and self-sufficient by the personal questionnaire (which is, for example. typical for introverts) and are also independent, they do not perceive so much humour and other characteristics of creative change. Based on the above, Fichnová (2013) concludes that individual psychological characteristics and individual personality traits contribute to the perception of environment in relation to creativity.

\section{Conclusions}

A review of studies indicates that demand for creativity and innovation in the work environment is growing. Consequently, if an organization has the ambition to handle claims arising in connection with the transition to a knowledge-based society, it is necessary to adopt a different way of management at the organizational level as well. It deals with a way of management which allows to fully develop the creative potential of employees.

\section{References}

Amabile, T. M. (1983). The Social Psychology of Creativity. New York: Springer - Verlag.

Amabile, T. (1998). How to Kill Creativity. Harvard Business Review, 76(5), 76-87.

Amabile, T. M., \& Hennessey, B. A. (1992). The Motivation for Creativity in Children. New York: Cambridge University.

Barron, F., \& Harrington, D. N. (1981). Creativity, Intelligence and Personality. Annual Review Psychology 32: 139-152.

Dacey, J. S., \& Lennon, K. H. (2000). Kreativita. Praha: Grada.

Eisenberger, R. (1996). Detrimental Effects of Reward: Reality or Myth? American Psychologist, 51(11), 1153-1166.

Ekvall, G. (1996). Organizational climate for creativity and innovation. European Journal of Work and Organizational Psychology, 5, 105-123.

Ekvall, G. (1999). Creative Climate. In M.A. Runco \& S.R. Pritzker, Encyclopedia of Creativity. Vol. 1. 403 - 412. San Diego: Elsevier.

Fichnová, K. (2013). Psychology of creativity for marketing communication. Noailles: Association Amitié Franco-Slovaque.

Florida, R., \& Goodnight, J. (2005). Managing for Creativity. Harvard Business Review, 83(7), 124-131. 


\section{Acta Technologica Dubnicae \\ volume 5, 2015, issue 2}

Hemlin, S. (2006). Creative knowledge environments for research groups in biotechnology. The influence of leadership and organizational support in universities and business companies. Scientometrics, 67(1), 121-142.

Hennessey, B. A., \& Amabile, T. M. (1988). The conditions of creativity. In R.J. Sternberg (Ed.), The nature of creativity: Contemporary psychological perspectives, 11-38. New York: Cambridge University.

Jurčová, M. (1995). Entrepreneurial Attitudes and their Barriers. In M. Jurčová \& M. Zelina (Eds.), Creativization and its barriers. Bratislava: SAP.

Jurčová, M., Kusá, D., \& Kováčová, E. (1995). Creative climate - dimensions and barriers. In M. Jurčová \& M. Zelina (Eds.), Creativization and its barriers. Bratislava: SAP.

Klijn, M., \& Tomic, W. (2010). A review of creativity within organizations from a psychological perspective. Journal of Management Development, 29(4), 322-343.

Kolajová, L. (2009). Týmová spolupráce: jak efektivně vést tým pro dosažení nejlepšich výsledkì. Praha: Grada.

Mathisen, G.E., Einarsen, S., Jorstad, K., \& Bronnick, K. S. (2004). Climate for work group creativity and innovation: Norwegian validation of the team climate inventory (TCS). Scandinavian Journal of Psychology, 45(5), 383392.

Mikuláštik, M. (2010). Tvořivost a motivace v práci manažera. Praha: Grada.

Mumford, M. D., Hester, K.S., \& Robledo, I.C. (2012). Creativity in Organizations: Importance and Approaches, Oxford: Elsevier.

Oldham, G.R., \& Cummings, A. (1996). Employee creativity: personal and contextual factors at work. Academy of Management Journal, 39(3), 607634.

Pagano, A. L. (1979). Learning and Creativity. Journal of Creative Behavior, 13(2), 127-138.

Paulus, P.B. (2000). Groups, teams, and creativity: the creative potential of ideagenerating groups. Applied Psychology: An International Review, 49(2), 237-262.

Puccio, G. J., \& Cabra, J. F. 2010. Organizational Creativity: A Systems Approach. In: J. C. Kaufman \& R.J. Sternberg (Eds.), The Cambridge Handbook of Creativity, 145-173. New York: Cambridge University.

Tamášová, V., \& Barnová, S. (2011). School climate as the determinant of the relationship between the level of students' resilience and school satisfaction. Acta Technologica Dubnicae, 1(1), 19-37.

Woodman, R. W., Sawyer, J.E., \& Griffin, R.W. (1993). Toward a theory of organizational creativity. Academy of Management Review, 18(2), 293-321.

Zelina, M., \& Jaššová, E. (1984). Tvorivost' - piata dimenzia. Bratislava: Smena. Žák, P. (2004). Kreativita a její rozvoj. Brno: Computer Press. 